\title{
Transtentorial transcollateral sulcus approach to the ventricular atrium: an endoscope-assisted anatomical study
}

\author{
Yasser Jeelani, MD, ${ }^{1}$ Abdulkerim Gokoglu, MD, ${ }^{2}$ Tomer Anor, PhD, ${ }^{1}$ Ossama AI-Mefty, MD, ${ }^{2}$ and \\ Alan R. Cohen, MD ${ }^{1}$
}

1Department of Neurosurgery, Boston Children's Hospital, Harvard Medical School; and 2Department of Neurosurgery, Brigham and Women's Hospital, Harvard Medical School, Boston, Massachusetts

\begin{abstract}
OBJECTIVE Conventional approaches to the atrium of the lateral ventricle may be associated with complications related to direct cortical injury or brain retraction. The authors describe a novel approach to the atrium through a retrosigmoid transtentorial transcollateral sulcus corridor.
\end{abstract}

\begin{abstract}
METHODS Bilateral retrosigmoid craniotomies were performed on 4 formalin-fixed, colored latex-injected human cadaver heads (a total of 8 approaches). Microsurgical dissections were performed under $3 \times$ to $24 \times$ magnification, and endoscopic visualization was provided by $0^{\circ}$ and $30^{\circ}$ rigid endoscope lens systems. Image guidance was provided by coupling an electromagnetic tracking system with an open source software platform. Objective measurements on cortical thickness traversed and total depth of exposure were recorded. Additionally, the basal occipitotemporal surfaces of 10 separate cerebral hemisphere specimens were examined to define the surface topography of sulci and gyri, with attention to the appearance and anatomical patterns and variations of the collateral sulcus and the surrounding gyri.
\end{abstract}

RESULTS The retrosigmoid approach allowed for clear visualization of the basal occipitotemporal surface. The collateral sulcus was identified and permitted easy endoscopic access to the ventricular atrium. The conical corridor thus obtained provided an average base working area of $3.9 \mathrm{~cm}^{2}$ at an average depth of $4.5 \mathrm{~cm}$. The mean cortical thickness traversed to enter the ventricle was $1.4 \mathrm{~cm}$. The intraventricular anatomy of the ipsilateral ventricle was defined clearly in all 8 exposures in this manner. The anatomy of the basal occipitotemporal surface, observed in a total of 18 hemispheres, showed a consistent pattern, with the collateral sulcus abutted by the parahippocampal gyrus medially, and the fusiform and lingual gyrus laterally. The collateral sulcus was found to be caudally bifurcated in 14 of the 18 specimens.

CONCLUSIONS The retrosigmoid supracerebellar transtentorial transcollateral sulcus approach is technically feasible. This approach has the potential advantage of providing a short and direct path to the atrium, hence avoiding violation of deep neurovascular structures and preserving eloquent areas. Although this approach appears unconventional, it may provide a minimally invasive option for the surgical management of selected lesions within the atrium of the lateral ventricle.

https://thejns.org/doi/abs/10.3171/2016.3.JNS151289

KEY WORDS endoscope-assisted microsurgery; collateral sulcus; ventricular atrium; supracerebellar; transtentorial; retrosigmoid; anatomy; surgical technique

$\mathrm{L}$ ESIONS in the atrium of the lateral ventricle can be challenging to resect because of their inherently deep location and the proximity to critical neurovascular structures. ${ }^{10}$ These structures include the choroidal arteries, the deep venous system, and, especially when in the dominant hemisphere, the adjacent cerebral cortex. ${ }^{8,13}$ The ventricular atrium is the most common site for the occurrence of both intraventricular neoplasms such as choroid plexus papillomas, meningiomas, and ependy- momas, and intraventricular vascular lesions such as arteriovenous malformations..$^{20}$ Conventional transtemporal approaches may injure eloquent cortex - surgery may thus be associated with various postoperative deficits, depending on the approach chosen. ${ }^{9}$

The supracerebellar transtentorial approach to the ventricular atrium provides a minimally invasive corridor by traversing the medially located collateral sulcus, while minimizing cortical disruption by virtue of the sulcus' an- 
atomical proximity to the ventricular atrium ${ }^{8}$ (Fig. 1). With proper head positioning, this approach may involve minimal retraction of the cerebellum and the occipital lobe. ${ }^{13}$ When compared with other conventional approaches to the atrium that involve various degrees of violation of eloquent cortex, this approach may result in a decreased incidence of postoperative deficits. ${ }^{13,14}$ The rationale for using the collateral sulcus as a distinct entry plane stems from it being the most consistent landmark on the basal occipitotemporal lobe. ${ }^{19}$ In addition, the collateral sulcus has been shown to be the deepest of the sulci on the occipitobasal surface, thus bringing the surgeon relatively closer to the ventricle, when compared with a transgyral approach. ${ }^{6} \mathrm{We}$ believe that the transcollateral approach will prove suitable in select cases, and that its translation into the operating theater will depend on careful case selection. Because its trajectory is optimally suited for lesions affecting the medial aspect of the atrium, this approach may find potential use especially in atrial arteriovenous malformations and meningiomas, in addition to the other common pathologies seen intraventricularly.

The aim of this study was 3-fold: 1) to demonstrate the microsurgical anatomy of a supracerebellar transtentorial transcollateral sulcus approach to the ventricular atrium through a retrosigmoid craniotomy; 2) to objectively evaluate the surgical corridor for such an approach; and 3) to demonstrate endoscopic views of the ventricular atrium thus obtained.

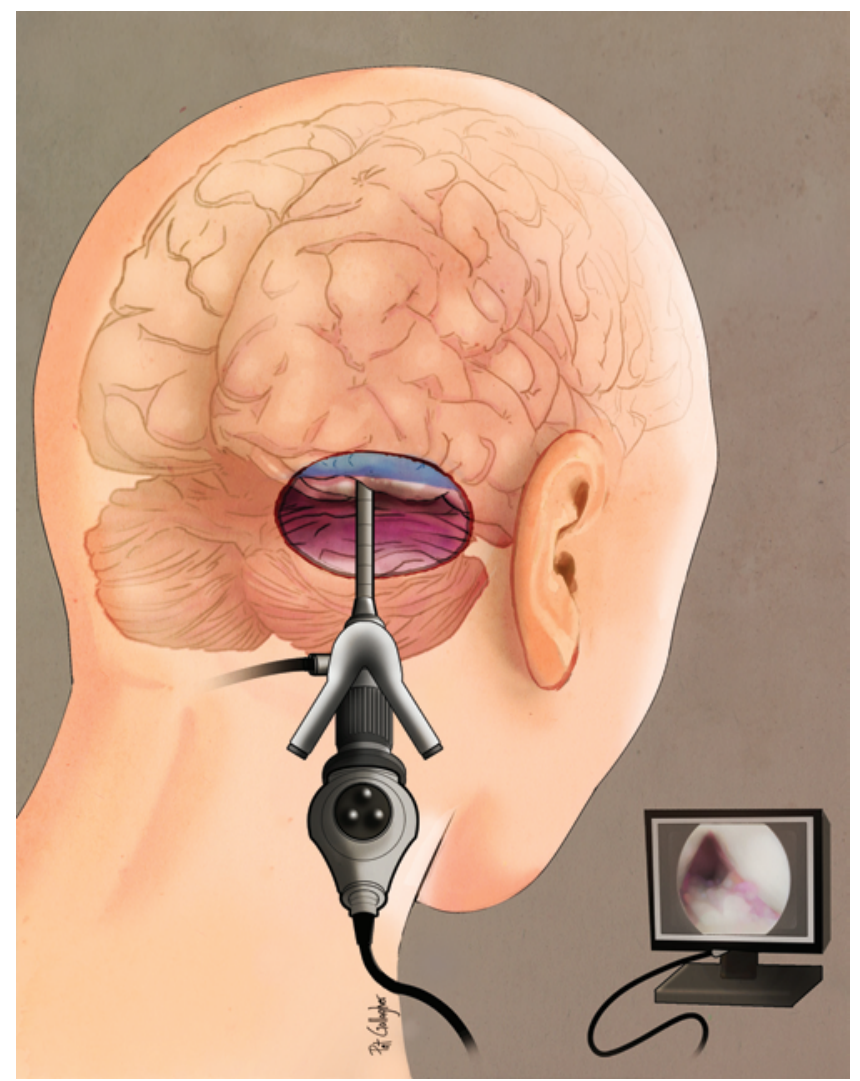

FIG. 1. Drawing showing the retrosigmoid supracerebellar transtentorial transcollateral sulcus approach to the lateral ventricle. Copyright Patrick Gallagher. Published with permission.

\section{Methods \\ Cadaveric Specimens}

Four adult, formalin-fixed, silicone-injected cadaveric heads were used to obtain 8 retrosigmoid exposures. Microsurgical dissections were performed under $3 x$ to $24 x$ magnification (Global Surgical). Endoscopic visualization was provided by a $2.7-\mathrm{mm}$-diameter, $0^{\circ}$ MINOP system (Aesculap) and by $4-\mathrm{mm}$-diameter, $0^{\circ}$ and $30^{\circ}$ rigid Hopkins lenses (Karl Storz).

Five separate, fresh adult brain specimens were examined to visualize and record the surface anatomy and the sulcal patterns on the occipitobasal surface in 10 additional cerebral hemispheres.

\section{Imaging and 3D Navigational Technique}

Image guidance was provided by a series of T1-weighted (spin echo) and T2-weighted MRI sequences loaded in Slicer 3D, an open source software application used to analyze MR images. A set of 7 predetermined (anatomical) fiducial points (e.g., tragus, vertex, medial and lateral canthi, external occipital protuberance) was collected with the tracker's sensor (probe) tip, followed by locating the fiducials on the corresponding MRI. A registration matrix between the 2 coordinate systems was computed using Slicer 3D's built-in iterative closest-point algorithm; the positional and rotational information of the tracker's tool was updated in real time, and the location was represented graphically in Slicer's 3D's interface.

The configuration of the tracking system included a midrange transmitter capable of generating a variable magnetic field, and a flexible sensor with an outer diameter of $0.9 \mathrm{~mm}$. The tracking system analyzed the variations in the magnetic field produced by the transmitter unit and computed the location and the orientation of the sensor's tip in real time.

\section{Measurements for Navigation}

A 3-mm-long sensor coil inserted into a narrow, 9-Fr Codman aspirator was used as the "probe" for navigation. The 3D spatial coordinates of points of interest were recorded off the probe in real time. The trajectory of the probe, depth at ventricular entry point, and conical projection of the surgical corridor were computed and graphically reconstructed (Fig. 2).
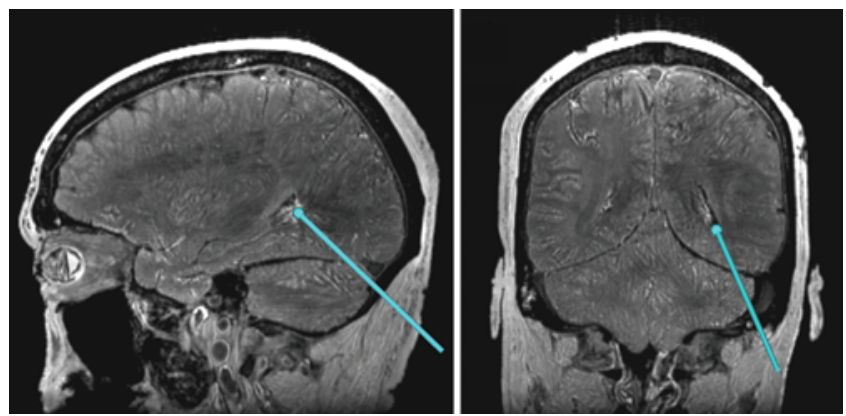

FIG. 2. The proposed trajectory to the ventricle was plotted using an electromagnetic tracking system and probe. The trajectory was planned on the sagittal (left), coronal (right), and hybrid axes. Figure is available in color online only. 


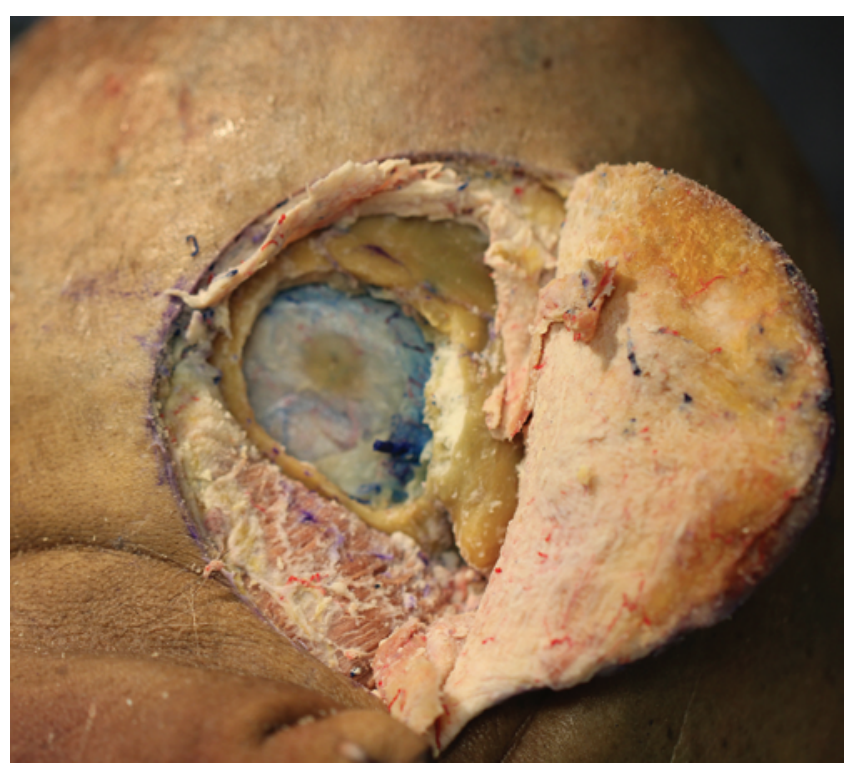

FIG. 3. Photograph of a cadaveric head showing a routine retrosigmoid craniotomy used for access. A single bur hole was placed, and the craniotomy was modeled around it. Figure is available in color online only.

\section{Microsurgical Approach}

The heads were positioned three-quarters prone in a Mayfield 3-pin holder. Such positioning allowed for gravity to aid in expanding the supracerebellar space and to align the endoscopic trajectory to the ventricular long axis. A conventional retrosigmoid craniotomy was performed bilaterally on each specimen. A point was marked $4 \mathrm{~cm}$ behind the external auditory meatus along a line extending from the zygomatic process to the external occipital protuberance. This mark roughly corresponded to the transverse-sigmoid sinus junction. The contour of the planned craniotomy was marked around this point, and a curvilinear skin marking was made to incorporate the planned craniotomy (Fig. 3). After the bone flap was removed, the transverse and sigmoid sinuses were skeletonized.

The dura mater was opened along the sinus, with a du- ral leaflet reflected rostrally toward the transverse sinus. This revealed the supracerebellar infratentorial space, limited superiorly by the tentorium. The space thus obtained varied from specimen to specimen, as did the presence and number of bridging tentorial veins.

\section{Tentorial Opening}

The tentorial opening was made wide enough to visualize the parahippocampal gyrus and lingual gyrus medially, and the fusiform gyrus more laterally. Given the more frequent occurrence of venous lakes in its medial third, ${ }^{15,24}$ the tentorium cerebelli was incised in a curvilinear fashion proceeding from lateral to medial, roughly halfway from the incisura to the edge of the transverse sinus in the anteroposterior plane. The tentorium was also inspected for the presence of any bridging veins or venous lakes between its leaflets. Any bridging hemispheric veins draining into the tentorial sinus were divided. The tentorial flap thus created was dropped onto the superior surface of the cerebellum, and the incision expanded until the abovementioned gyri were visualized (Fig. 4).

\section{Endoscope Introduction}

After localization of the collateral sulcus, the previously described probe was used to plot an optimal trajectory to the ipsilateral ventricle. Using navigation, the trajectory was planned in real time, aimed at involving the minimum thickness of cortex to enter the ventricle. The angle of the trajectory was also planned with the aim to make the endoscope align with the long axis of the lateral ventricular cavity, to allow for maximum visualization. Under such guidance, a $2.7-\mathrm{mm}, 0^{\circ}$ endoscope lens with introducer was advanced into the ventricle. Subsequently, a largerdiameter $30^{\circ}$-angled rigid Hopkins lens was used for exploration. In all 8 hemispheres, the ventricle was entered in the first attempt in this fashion. Following the introduction of the endoscope, the sulcal opening thus created was expanded using bimanual microsurgery. The sulcal opening was extended variably in this way, till the opening was large enough to accommodate a microsurgical forceps in addition to the endoscope lens (Fig. 5).
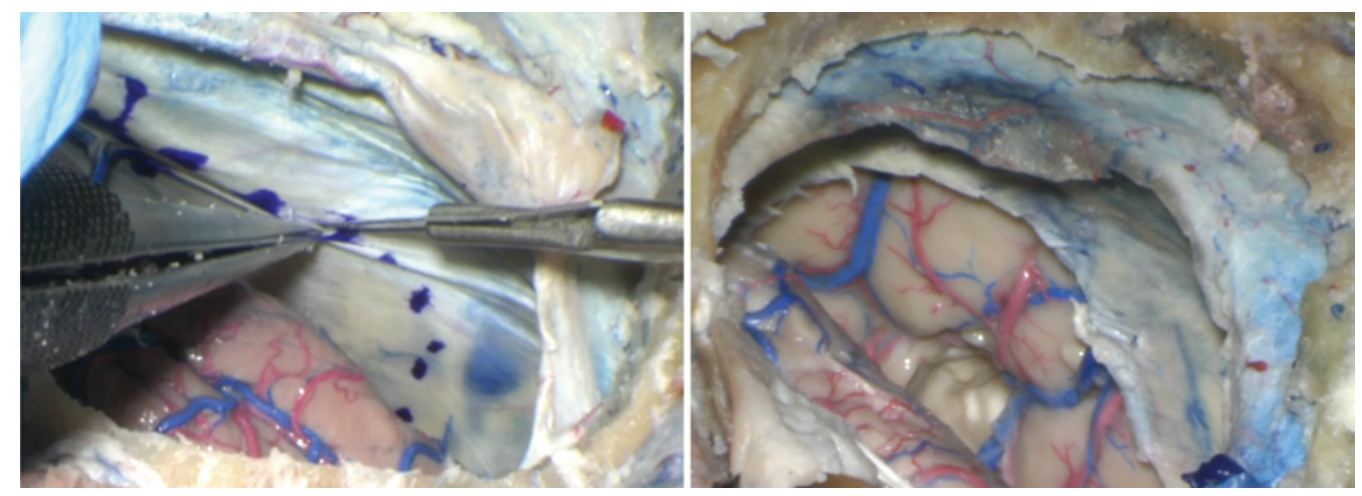

FIG. 4. Left: Planning the tentorial opening, which was aimed at maximizing exposure of the basal occipitotemporal area. Right: The tentorial incision was extended until gyri on either side of the collateral sulcus became visible. The tentorial leaflet thus created was allowed to rest on the superior surface of the cerebellar hemisphere. Figure is available in color online only. 

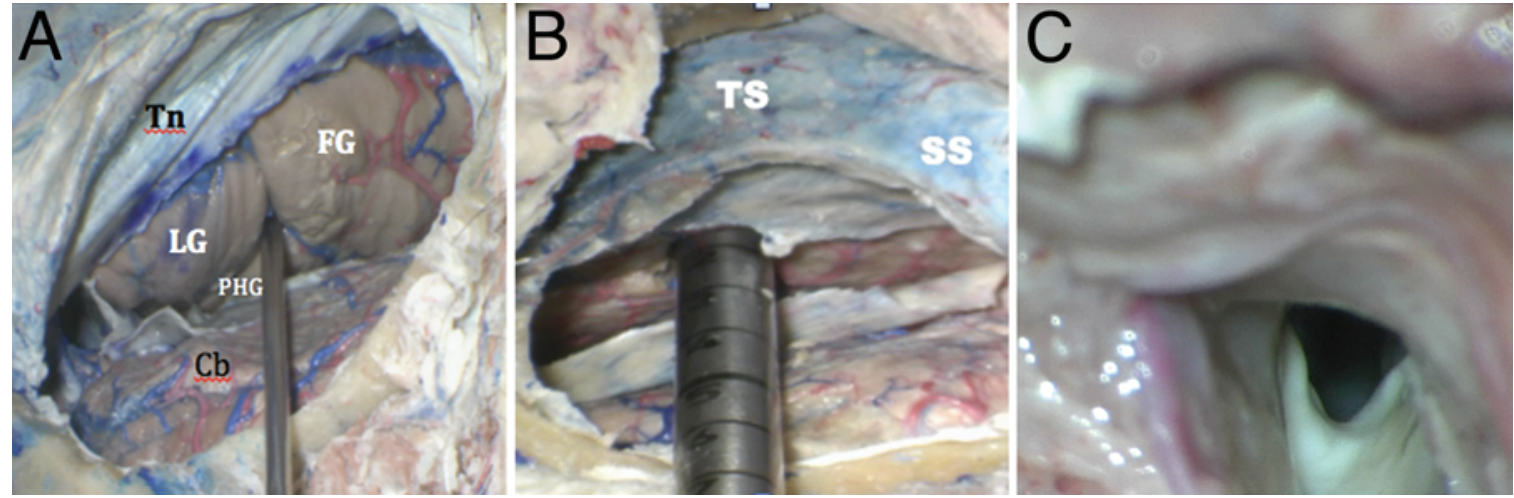

FIG. 5. A: Using the probe under navigational guidance to plan the trajectory into the ventricular atrium after the collateral sulcus is identified. $\mathrm{B}: \mathrm{A} 0^{\circ}$ 2.3-mm-diameter endoscope (with trocar) is introduced into the ipsilateral ventricle. C: The corridor to the ventricle obtained using the endoscope may then be used for bimanual microsurgical access. $\mathrm{Cb}=$ cerebellum; FG = fusiform gyrus; $L G$ = lingual gyrus; $P H G$ = parahippocampal gyrus; $S S=$ sigmoid sinus; $\mathrm{Tn}=$ tentorium; $\mathrm{TS}$ = transverse sinus. Figure is available in color online only.

\section{Results}

\section{Endoscopic Ventricular Anatomy}

The entire lumen of the ipsilateral lateral ventricle was visualized by advancing the endoscope through the opening in the collateral sulcus, and digital photographs were obtained. The ventricular anatomy of the atrium was subsequently defined in detail using $4-\mathrm{mm}, 0^{\circ}$, and $30^{\circ}$ rigid Hopkins endoscope lenses.

Immediately upon entering the ventricular atrium, the medial wall was seen. A prominent bulge that represented the calcar avis was noted. The calcar avis is formed by the underlying intraventricular projection of the calcarine sulcus that lies just medial to it. The forceps major was seen superior to the calcar avis, also on the medial wall. Advancing the endoscope anteriorly along the medial wall revealed the posterior part of the septum pellucidum. Focusing the endoscope on the lateral wall of the atrium, the tapetum was visualized. The tapetum, in turn, formed the lateral wall of the atrial roof by joining the splenium of the corpus callosum that arose medially. Seen on the floor of the atrium was the collateral eminence, a ridge that marks the inward impression of the collateral sulcus into the lumen of the ventricular atrium (Fig. 6).

Choroid plexus was present variably in the ventricular atrium. In 1 approach, a prominent vein representing the lateral atrial vein was seen within the plexus. In 4 approaches, a prominent tuft of choroid plexus (glomus) was seen abutting the medial surface of the atrium.

\section{Objective Exposure Metrics}

Data on measurement of the distance between the surface of the brain and the ventricle, and on the total depth of ventricular access from the craniotomy margins, were obtained using the Slicer 3D interface. The results are summarized in Table 1.

\section{Discussion}

The atrium of the lateral ventricle is a fairly common location for neoplastic and vascular lesions. ${ }^{1,2,5,17}$ Choroid plexus tumors, ependymomas, and meningiomas, as well as arteriovenous malformations, occur with varying frequency in the region..$^{2,4}$ In fact, although intraventricular meningiomas represent a small fraction of meningiomas overall, more than three-quarters of them occur in the atrium. ${ }^{7,12,16,18}$ Similarly, arteriovenous malformations occurring in the atrium represent a distinct subset of vascular malformations that can be difficult to resect due to their deep location, lack of cortical representation, and their commingling with the choroid plexus. ${ }^{1,2}$

Conventional approaches to the atrium have been previously summarized by Kawashima et al. ${ }^{10}$ Broadly, the various approaches can be classified as anterior, posterior, and lateral (Table 2). Many of these approaches are limited by the need to traverse eloquent brain. Minimally invasive endoscopic counterparts of the same approaches may present similar operative risks due to eloquent cortical injury, in addition to providing a narrower corridor to the ventricular atrium.

The first description of a supracerebellar transtentorial approach being used to access the mediobasal temporal region was by Voigt and Yaşargil in 1976.11,22 The supracerebellar transtentorial approach to the ventricular atrium, on the other hand, was demonstrated more recently on cadavers by Kawashima et al., and then by Izci et al. ${ }^{8,10}$ In 2013, Marcus et al. reported a series of 2 patients, which was the first reported instance of the use of such an approach for resection of an intraventricular tumor. ${ }^{13}$ A similar approach to the posteromedial temporal region has been described in which a sitting position is used to obtain a direct route to the posterior fusiform and lingual gyri. ${ }^{23}$ In all of the abovementioned studies, the authors performed a suboccipital craniotomy to gain exposure to the supratentorial space. Our study represents a modification of such previously described approaches to access the ventricular atrium instead.

In the current study, we used a retrosigmoid approach instead of a midline or paramedian suboccipital craniotomy for the following reasons: 1) the retrosigmoid craniotomy provides a wider range of movement of the endoscope, especially along the sagittal plane, thus permitting better visualization of the atrial roof; 2) a "swing-out" 


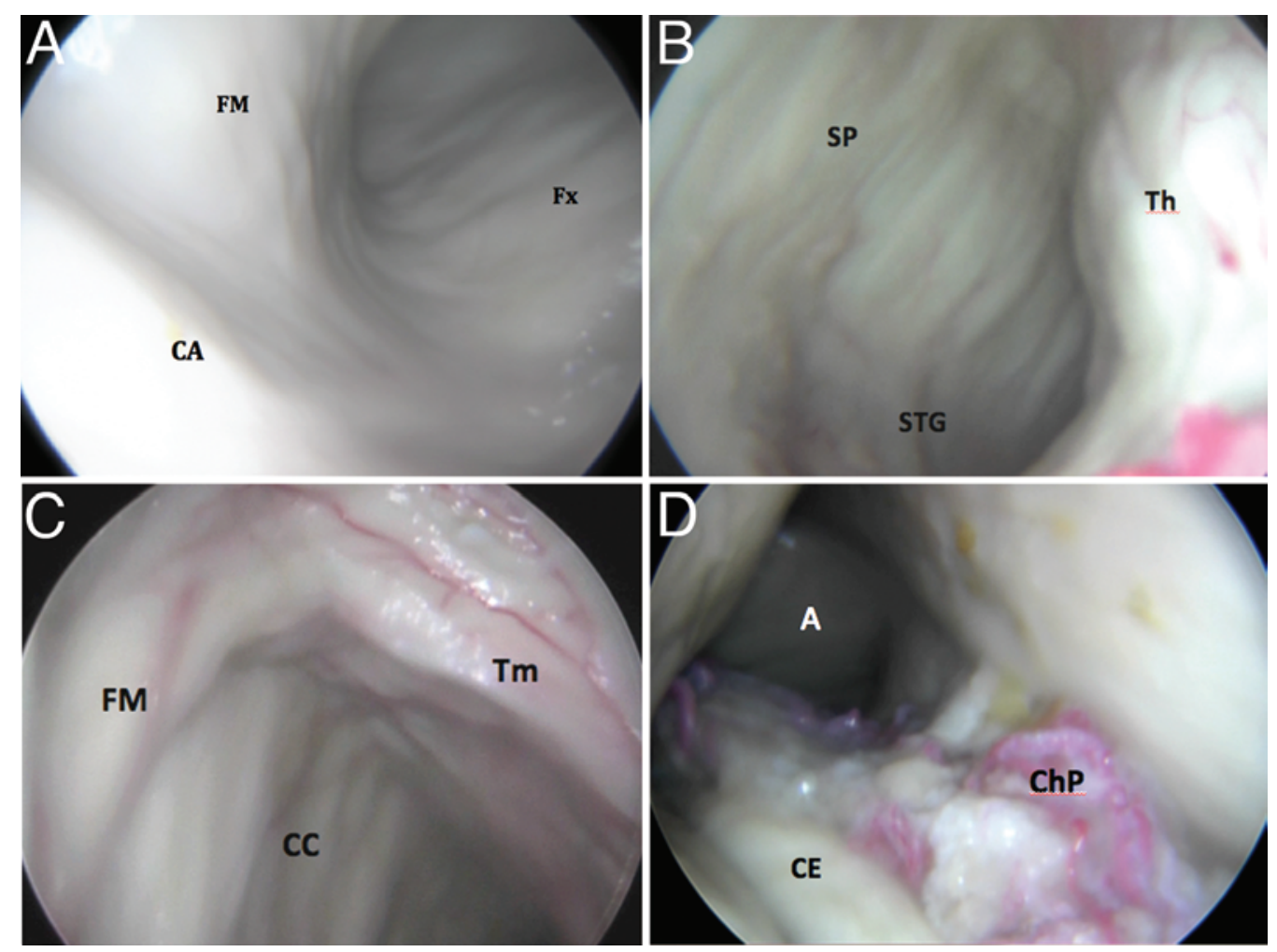

FIG. 6. Endoscopic anatomy of the ventricular atrium as seen through the transcollateral corridor. A: The medial wall of the right lateral ventricle with a prominent bulge of the calcar avis (CA). Also seen are impressions of the forceps major (FM) and the fornix (Fx). B: View of the lateral wall of the right atrium showing the thalamus (Th). The septum pellucidum (SP) is seen on the opposite (medial) wall, as is the striatothalamic groove (STG). C: The roof of the right atrium formed by the splenium of the corpus callosum (CC) and the forceps major on the medial side in conjunction with the tapetum (Tm) that forms most of the lateral wall. D: The floor of the right lateral ventricular atrium $(A)$, as seen with a $30^{\circ}$-angled lens. Note the collateral eminence $(C E)$ formed by the invagination of the collateral sulcus into the atrial lumen, and the presence of choroid plexus (ChP). Figure is available in color online only.

more laterally allows for more extensive medial wall exploration; 3) patient positioning for a midline or paramedian suboccipital craniotomy may require the patient to be sitting, and thus may predispose to an increased risk of air embolism, in addition to the difficulty in upward visualization; and 4) a more lateral approach to the atrium may reduce the need for dividing the median bridging tentorial veins near the vermis, coagulation of which may result in venous infarction..$^{14}$ In fact, for operative procedures requiring incision of the tentorium, some authors have recommended preoperative MR venous angiography to identify any venous lakes lying within. In fact, a basal vein of Rosenthal seen draining a tentorial sinus can be considered a contraindication to the supracerebellar transtentorial approach. ${ }^{21,23}$

An adequately positioned tentorial opening is crucial in identifying and accessing the collateral sulcus on the basal surface of the ipsilateral occipitotemporal lobe, because the collateral sulcus can be highly variable in morphology. ${ }^{6,19}$ Such visualization is indispensible in this context due to the highly variable surface topography of the surrounding gyri. ${ }^{3}$ In a study of 30 cadaveric cerebral hemispheres, Chau et al. noted that the collateral sulcus was present in all, wedged between the medial (parahippocampal and lingual) occipitotemporal gyrus and the lateral (fusiform) occipitotemporal gyri. In the same study, Chau et al. also postulated that the collateral sulcus could be divided into 3 parts: the anterior rhinal, middle proper, and the caudal collateral sulcus, while noting that the caudal collateral sulcus was seen bifurcated into posteromedial and posterolateral branches in $87 \%$ of specimens. Our observations across 18 cerebral hemispheres reaffirmed this high incidence of posteriorly bifurcated collateral sulci (approximately 77\%). An inadequate tentorial opening

TABLE 1. Approach metrics for the retrosigmoid supracerebellar transtentorial transcollateral sulcus approach to the atrium of the lateral ventricle

\begin{tabular}{lcl}
\hline Measurement Variable & Value $(\mathrm{cm})^{*}$ & Remarks \\
\hline Distance: bone to ventricle & $4.5(3.8-5.1)$ & Shorter distance provides greater endoscopic maneuverability \\
\hline Cortex traversed & $1.4(1.2-1.7)$ & Minimal cortical transgression \\
\hline
\end{tabular}

\footnotetext{
* Averaged over 8 exposures in 4 heads.
} 
TABLE 2. Approaches to the ventricular atrium: summary of different surgical routes and corresponding potential complications

\begin{tabular}{|c|c|c|c|c|}
\hline Category & Surgical Approach & Cortical Transgression & Remarks & Potential Complications \\
\hline Anterior & Distal sylvian & Posterior insular cortex & Wide retraction of sylvian fissure & Auditory \& visual deficits ${ }^{11}$ \\
\hline \multirow[t]{4}{*}{ Posterior } & Posterior transcortical & $\begin{array}{l}\text { Superior parietal lobule } \\
\text { behind postcentral } \\
\text { sulcus/via temporo- } \\
\text { parietal junction }\end{array}$ & $\begin{array}{l}\text { Long operative distance, difficulty } \\
\text { accessing vascular pedicle of } \\
\text { tumor }\end{array}$ & $\begin{array}{l}\text { Visual field deficit (either hemisphere); } \\
\text { aphasia, agnostic disorders (domi- } \\
\text { nant side), visuospatial dysfunction } \\
\text { (nondominant side) }\end{array}$ \\
\hline & Posterior transcallosal ${ }^{13}$ & Splenium & Need for ventricles to be dilated & $\begin{array}{l}\text { Possible visual-verbal disconnection, }{ }^{14} \\
\text { increased seizure risk, }{ }^{17} \text { mutism }{ }^{23}\end{array}$ \\
\hline & $\begin{array}{l}\text { Occipital (interhemispheric } \\
\text { transprecuneus), or its } \\
\text { transfalcine variant }\end{array}$ & Precuneus & $\begin{array}{l}\text { Deep \& narrow working corridor; } \\
\text { suited for lesions in the medial } \\
\text { atrial wall }\end{array}$ & Memory disturbance \\
\hline & $\begin{array}{l}\text { Supracerebellar transten- } \\
\text { torial }^{9}\end{array}$ & CS & $\begin{array}{l}\text { Narrow approach through floor of } \\
\text { atrium; CS morphology variable }\end{array}$ & None (2 patients reported so far) $)^{16}$ \\
\hline \multirow[t]{2}{*}{ Lateral } & Transtemporal & $\begin{array}{l}\text { Middle/inferior temporal } \\
\text { gyrus }\end{array}$ & $\begin{array}{l}\text { Corticotomy may involve optic } \\
\text { radiation }\end{array}$ & $\begin{array}{l}\text { Aphasia (dominant side), quadran- } \\
\text { tanopia }\end{array}$ \\
\hline & Subtemporal & $\begin{array}{l}\text { Inferior temporal/occipi- } \\
\text { totemporal gyrus }\end{array}$ & $\begin{array}{l}\text { Preferred for accessing anteroinfe- } \\
\text { rior atrium }\end{array}$ & $\begin{array}{l}\text { Venous infarction (when vein of Labbé } \\
\text { is endangered) }\end{array}$ \\
\hline
\end{tabular}

CS = collateral sulcus

may potentially impede the ability of the operator to perform bimanual, endoscope-assisted microsurgery through the created corridor.

The bifurcation point of the collateral sulcus, when present, is a useful guide to the entry point along the trajectory into the ventricle. Huntgeburth and Petrides ${ }^{6}$ noted that this bifurcation corresponded to the level of the cingulate isthmus in more than $90 \%$ of instances in their study of 40 brain MRIs. This, along with knowledge of the relationship of the collateral sulcus with the splenium and cingulate isthmus, can provide a rough estimate of one's position along the axial plane of the basal occipitotemporal surface. Staying behind this point may, in theory, prevent a trajectory too steep to provide visualization of the entire ventricular atrium. On the other hand, placing the endoscope too far behind this point may result in damage to the posteromedial fusiform gyrus, resulting in prosopagnosia or dyslexia. ${ }^{19,21}$

Once inside the ventricle, the endoscopic anatomy was clearly defined. With a retrosigmoid approach, the trajectory is inherently aimed more medially, providing excellent views of the medial ventricular wall. Further exploration of the lateral ventricular wall can be aided by the use of an angled endoscope lens. Advancing the endoscope along the long axis of the ventricle may also provide improved visualization of the body of the ventricle. This may have implications in resection of an intraventricular tumor, and in ruling out residual tumor during resection.

\section{Study Limitations}

The supracerebellar transtentorial transcollateral sulcus approach provides a small transsulcal opening, with a narrow working distance, making microsurgical resection of atrial lesions difficult if endoscopy alone cannot be relied on. For vascular lesions, bleeding control may be challenging when using an endoscope under such circumstances. Finally, caution must be exercised in extrapolating the results from formalin-fixed cadaver specimens to the living patient.

\section{Conclusions}

We have demonstrated the technical feasibility of an endoscope-assisted microsurgical approach to the atrium of the lateral ventricle through a retrosigmoid supracerebellar transtentorial transcollateral sulcus, using cadaveric specimens. This approach may have the advantages of avoiding cortical injury and consequent operative deficits seen with other conventional minimally invasive approaches to the region, and may be applicable in selected cases for resection of lesions in the atrium of the lateral ventricle. Selection of this approach for the right indication may prove to be crucial for a safe and satisfactory outcome.

\section{References}

1. Barrow DL, Dawson R: Surgical management of arteriovenous malformations in the region of the ventricular trigone. Neurosurgery 35:1046-1054, 1994

2. Batjer H, Samson D: Surgical approaches to trigonal arteriovenous malformations. J Neurosurg 67:511-517, 1987

3. Chau AM, Stewart F, Gragnaniello C: Sulcal and gyral anatomy of the basal occipital-temporal lobe. Surg Radiol Anat 36:959-965, 2014

4. Fornari M, Savoiardo M, Morello G, Solero CL: Meningiomas of the lateral ventricles. Neuroradiological and surgical considerations in 18 cases. J Neurosurg 54:64-74, 1981

5. Guidetti B, Delfini R, Gagliardi FM, Vagnozzi R: Meningiomas of the lateral ventricles. Clinical, neuroradiologic, and surgical considerations in 19 cases. Surg Neurol 24:364370,1985

6. Huntgeburth SC, Petrides M: Morphological patterns of the collateral sulcus in the human brain. Eur J Neurosci 35:1295-1311, 2012

7. Imielinski BL, Kopczynski SM: Meningioma within the lateral ventricle. Neurochirurgia (Stuttg) 13:124-130, 1970

8. Izci Y, Seçkin H, Ateş O, Başkaya MK: Supracerebellar transtentorial transcollateral sulcus approach to the atrium 
of the lateral ventricle: microsurgical anatomy and surgical technique in cadaveric dissections. Surg Neurol 72:509-514, 2009

9. Jun CL, Nutik SL: Surgical approaches to intraventricular meningiomas of the trigone. Neurosurgery 16:416-420, 1985

10. Kawashima M, Li X, Rhoton AL Jr, Ulm AJ, Oka H, Fujii K: Surgical approaches to the atrium of the lateral ventricle: microsurgical anatomy. Surg Neurol 65:436-445, 2006

11. Kawashima M, Rhoton AL Jr, Matsushima T: Comparison of posterior approaches to the posterior incisural space: microsurgical anatomy and proposal of a new method, the occipital bi-transtentorial/falcine approach. Neurosurgery 51:1208-1221, 2002

12. Lyngdoh BT, Giri PJ, Behari S, Banerji D, Chhabra DK, Jain VK: Intraventricular meningiomas: a surgical challenge. J Clin Neurosci 14:442-448, 2007

13. Marcus HJ, Sarkar H, Mindermann T, Reisch R: Keyhole supracerebellar transtentorial transcollateral sulcus approach to the lateral ventricle. Neurosurgery 73 (2 Suppl Operative):E295-E301, 2013

14. Moftakhar R, Izci Y, Başkaya MK: Microsurgical anatomy of the supracerebellar transtentorial approach to the posterior mediobasal temporal region: technical considerations with a case illustration. Neurosurgery 62 (3 Suppl 1):1-8, 2008

15. Muthukumar N, Palaniappan P: Tentorial venous sinuses: an anatomic study. Neurosurgery 42:363-371, 1998

16. Nagata S, Sasaki T: Lateral transsulcal approach to asymptomatic trigonal meningiomas with correlative microsurgical anatomy: technical case report. Neurosurgery 56 (2 Suppl):E438, 2005

17. Nagib MG, O'Fallon MT: Lateral ventricle choroid plexus papilloma in childhood: management and complications. Surg Neurol 54:366-372, 2000

18. Nakamura M, Roser F, Bundschuh O, Vorkapic P, Samii M: Intraventricular meningiomas: a review of 16 cases with reference to the literature. Surg Neurol 59:491-504, 2003

19. Novak K, Czech T, Prayer D, Dietrich W, Serles W, Lehr S, et al: Individual variations in the sulcal anatomy of the basal temporal lobe and its relevance for epilepsy surgery: an anatomical study performed using magnetic resonance imaging. J Neurosurg 96:464-473, 2002
20. Timurkaynak E, Rhoton AL Jr, Barry M: Microsurgical anatomy and operative approaches to the lateral ventricles. Neurosurgery 19:685-723, 1986

21. Türe U, Harput MV, Kaya AH, Baimedi P, Firat Z, Türe H, et al: The paramedian supracerebellar-transtentorial approach to the entire length of the mediobasal temporal region: an anatomical and clinical study. Laboratory investigation. J Neurosurg 116:773-791, 2012

22. Voigt K, Yaşargil MG: Cerebral cavernous haemangiomas or cavernomas. Incidence, pathology, localization, diagnosis, clinical features and treatment. Review of the literature and report of an unusual case. Neurochirurgia (Stuttg) 19:5968,1976

23. Weil AG, Middleton AL, Niazi TN, Ragheb J, Bhatia S: The supracerebellar-transtentorial approach to posteromedial temporal lesions in children with refractory epilepsy. J Neurosurg Pediatr 15:45-54, 2015

24. Yonekawa Y, Imhof HG, Taub E, Curcic M, Kaku Y, Roth $\mathrm{P}$, et al: Supracerebellar transtentorial approach to posterior temporomedial structures. J Neurosurg 94:339-345, 2001

\section{Disclosures}

The authors report no conflict of interest concerning the materials or methods used in this study or the findings specified in this paper.

\section{Author Contributions}

Conception and design: Jeelani, Al-Mefty, Cohen. Acquisition of data: Jeelani, Gokoglu, Anor. Analysis and interpretation of data: Jeelani, Gokoglu, Anor, Cohen. Drafting the article: Jeelani. Critically revising the article: Al-Mefty, Cohen. Reviewed submitted version of manuscript: all authors. Approved the final version of the manuscript on behalf of all authors: Jeelani. Study supervision: Cohen.

\section{Correspondence}

Yasser Jeelani, Department of Neurosurgery, Boston Children's Hospital, Harvard Medical School, 300 Longwood Ave., Boston, MA 02115. email: yasserjeelani@gmail.com. 